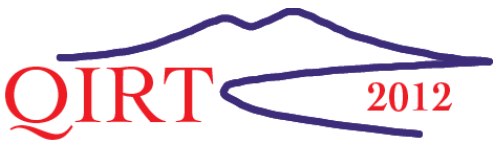

\title{
Regulations governing the use of non-certified instruments within the Oil, Gas \& Petrochemical Industries.
}

By M. Halliday*

\author{
*CorDEX Instruments Ltd, Unit 1, Owens Road, Skippers Lane Industrial Estate, Middlesbrough, \\ Teesside, United Kingdom, marcus.halliday@cord-ex.com
}

\begin{abstract}
This paper will discuss the regulations \& guidelines relating to the use of non-certified hand-held instruments within potentially hazardous (explosive) working environments.

Regular inspections within the Oil, Gas \& Petro-Chemical industry are mandatory under government legislation. This legislation puts the onus on the plant operators to ensure continued safe operation of their facilities, a major part of which is to ensure equipment is operating within specified safe temperature limits required to prevent explosions.
\end{abstract}

For example since the early nineties these industries have gradually introduced the use of infrared thermography as a useful method of NDT for aiding their preventative maintenance programs.

As more emphasis is placed on safety within hazardous locations, there will be a greater increase in the number of personnel carrying out inspection/maintenance without a full understanding of the regulations governing the use noncertified equipment in hazardous locations.

Specifically the author will discuss the importance of adhering to both DSEAR regulations and the ATEX Directives and how they affect the use of non-certified hand-held instruments within potentially explosive atmospheres.

By providing this information, it will enable potential employees the ability to use their technology safely and ultimately improve the reliability and productivity of their facility.

\section{Introduction}

A potentially hazardous environment is defined as a location in which the surrounding atmosphere could/does contain sufficient concentrations of potentially explosive, vapours or gases. This scenario is often depicted by the combustion or fire triangle. (See Figure 1).

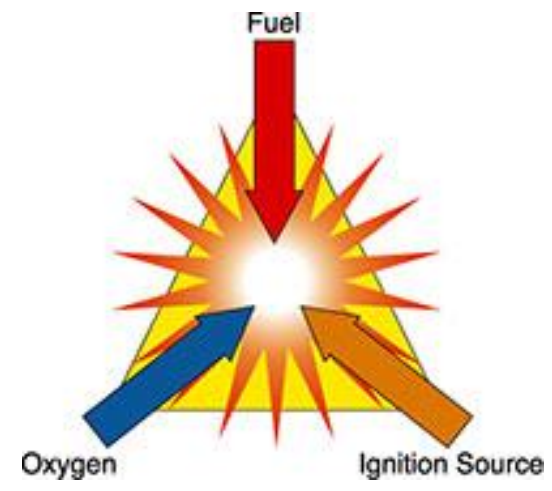

Fig. 1. Combustion Triangle

An explosion occurs as a result of a chemical reaction when these three key environmental conditions are all present at optimal levels.

By removing one of the three key elements, the risk of an explosion occurring is reduced. Of course we cannot remove oxygen; we are unable to remove the fuel either, so we need to look at removing the ignition source. The most likely source of ignition would come from electrical apparatus, so the simplest way would be to remove any electrical equipment from the hazardous area. Unfortunately this is also difficult as fixed machinery is required for the various manufacturing processes within these environments, so we are left with minimizing the amount of portable electrical 
equipment being taken into a hazardous area. These environments can be predominantly found in chemical manufacturing, oil \& gas platforms, refineries, underground mining, petrol station forecourts, paint manufacturing, cosmetic manufacturing etc.

\section{Hazardous Area Classification}

The hazardous areas that are present within these particular facilities can be classified using specific criteria and should be carried out in accordance with the following standard:

- $\quad$ IEC 60079-10-1 [1]

Two main criteria to be considered when classifying a potentially hazardous vapour environment are:

1. The area where the probability of the hazardous vapour or gas being present, referred to as "zones".

2. An understanding of the particular type of vapours \& gases present; these are then categorised into "gas groups".

\subsection{Zones}

The majority of these facilities process substantial quantities of potentially explosive liquids and gases and the concentration of vapours will vary in different areas of the facility. Some areas will have these vapours present for long periods or even at all times, others areas will only experience the presence of ignitable vapours at certain times. Due to the varying levels of vapours present on these facilities they are catagorised into sections known as zones. The method of determining the type of zone depends on the amount of time a potentially explosive vapour is present. (See Table 1).

Table 1. Zone Characteristics.

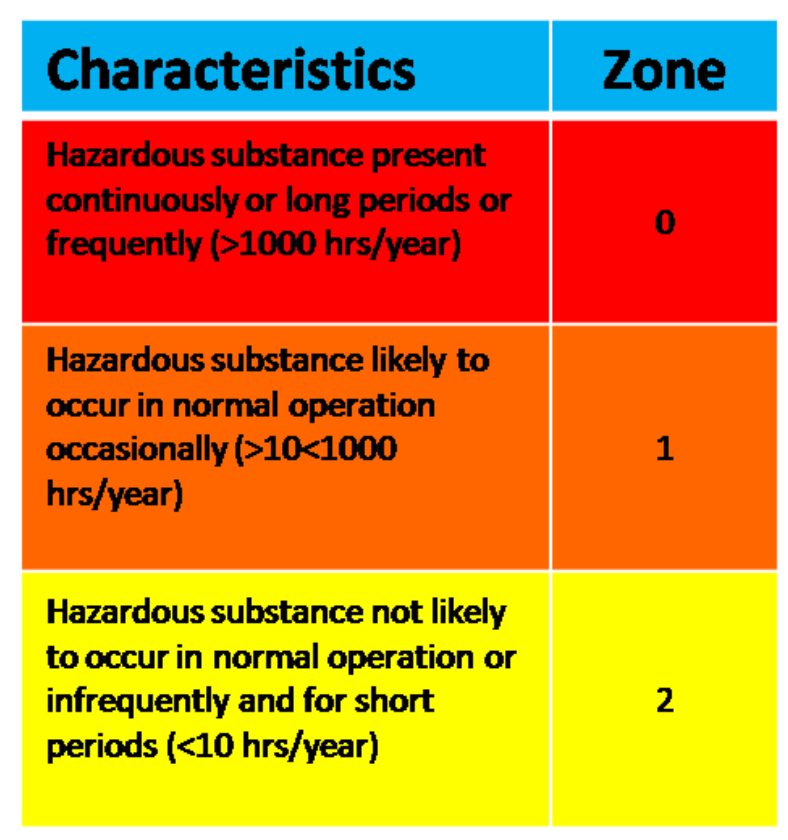

\subsection{Gas Groups}

Every explosive vapour or gas comprises of different chemical properties that will determine the probability and severity of an explosion. Each gas falls into one of three gas sub-groups IIA, IIB \& IIC, the sub-group that a gas falls into is determined by how volatile/destructive they would be if ignited, where gases in sub-group IIC are more volatile/destructive than those in IIA. (See Table 2). 
Table 2. Example gas \& vapours and there corresponding gas group.

\begin{tabular}{|c|c|}
\hline $\begin{array}{c}\text { Gas or } \\
\text { Vapour }\end{array}$ & $\begin{array}{c}\text { Gas } \\
\text { Group }\end{array}$ \\
\hline Methane & IIA \\
\hline Propane & IIA \\
\hline Petrol & IIA \\
\hline Ethylene & IIB \\
\hline Acetylene & IIC \\
\hline Hydrogen & IIC \\
\hline
\end{tabular}

These gas groups also indicate the level of energy required to ignite the gas, where group IIA requiring greater energy whilst group IIC requires lower energy to ignite.

\section{Regulations}

Companies within the EU with facilities containing potentially explosive atmospheres must adhere to specific regulations known as the ATEX directive. This is to ensure that suitable steps are taken to protect workers from explosion risk in areas with potentially explosive atmospheres. Before a workplace becomes operational for the first time areas where potentially explosive atmospheres may be present must be verified as being safe by a person or organisation competent in the field of explosion protection.

The ATEX Directive is the collective name given to the following two European Directives for controlling explosive atmospheres:

\section{Directive 99/92/EC}

Commonly known as 'ATEX 137 ' or the 'ATEX Workplace Directive' - These requirements highlight the minimum for improving the health and safety protection of workers potentially at risk from explosive atmospheres.

\section{Directive 94/9/EC}

Commonly known as 'ATEX 95' or 'the ATEX Equipment Directive' - These requirements are for manufacturers of equipment destined for use within potentially explosive atmospheres.

\section{‘ATEX 137’ - Directive 99/92/EC}

Within the Directive 99/92/EC [2], there are 7 sections specifically highlighting the obligations of the employer. These sections known as articles are detailed below:

\section{Article 3: Prevention of and protection against explosions.}

Regularly review company policies and procedures for the prevention and protection against explosions and to ensure the health and safety of workers.

\section{Article 4: Assessment of explosion risks}


Employers shall undertake to assess the specific explosion risks arising from the potential presence of explosive atmospheres.

\section{Article 5: General obligations}

Employers shall ensure the working environment is suitable for workers to perform their duties and that appropriate supervision is provided to ensure the safety and health of workers.

\section{Article 6: Duty of coordination}

Employers shall effectively co-ordinate and document the implementation of health \& safety measures for workers; this includes a workplace where there may potentially be workers from various companies working together; for example contractors.

\section{Article 7: Places where explosive atmospheres may occur}

Where explosive atmospheres may occur, an employer must:

1. Classify places where explosive atmospheres may occur into zones in accordance with Annex I of the directive [3] as discussed earlier.

2. Ensure that the minimum requirements highlighted in Annex II of the directive [4] are followed.

3. Where explosive atmospheres may occur in such quantities as to endanger the health and safety of workers employers shall place signs at the points of entry in accordance with Annex III of the directive. (See figure 2).

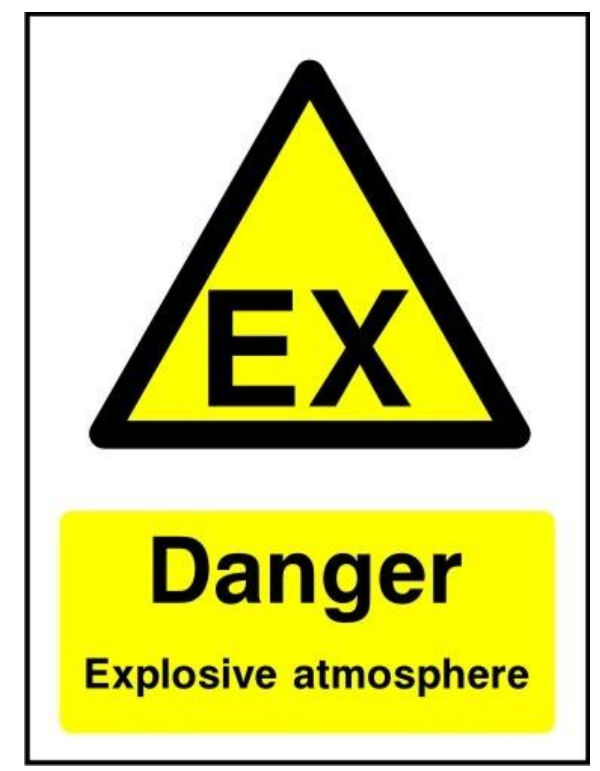

Fig. 2. Example warning sign.

The warning sign for places where explosive atmospheres may occur vary in design but must incorporate the following distinctive features:

- $\quad$ Display a triangular shape as shown in Figure 2.

- The triangle must consist of black letters on a yellow background with black edging - the yellow part of the triangle to take up at least $50 \%$ of the area of the sign. 
Refers to the drawing up and maintaining of documentation in line with obligations set out in Article 4, this documentation is generally referred to as the "explosion proof document", this document must exhibit the following:

1. That explosion risks have been determined and assessed.

2. The areas which have been classified into zones in accordance with Annex I of the Directive [5].

3. The areas where the minimum requirements set out in Annex II of the directive [6] will apply.

4. That the workplace and equipment, including warning devices, are designed, operated and maintained with specific regard for safety.

5. That adequate measures have been taken to achieve the aims of the Directive.

6. That in accordance with Council Directive 89/655/EEC(10) [7], suitable arrangements have been made for the safe use of work equipment.

The 'explosion protection document' must be drawn up prior to the commencement of any work and must be revised when the workplace, work equipment or organisation of the work is subject to any significant changes or alterations.

\section{Article 9: Special requirements for work equipment and workplaces}

Depending on the date when a particular workplace containing potentially explosive atmospheres became operational, will determine when the minimum requirements of the Directive must be complied with.

- If the workplace containing a potentially explosive atmosphere came into operation after the $30^{\text {th }}$ June 2003 then it must comply with the minimum requirements of Directive 99/92/EC

- If the workplace containing a potentially explosive atmosphere came into operation before the $30^{\text {th }} \mathrm{June} 2003$ they had 3 years from the date of first operations to ensure the workplace complied with the minimum requirements of Directive 99/92/EC. [8]

Since the 30th June 2003, any restructuring, alterations or extensions carried out within the workplace where a potentially explosive atmosphere may be present, necessary actions should be taken to ensure that they also comply with the minimum requirements set out in Directive 99/92/EC. [9]

\subsection{Regulation Enforcement}

In the UK the requirements of Directive 99/92/EC [10] (ATEX 137) are implemented through regulations 7 [11] and 11 [12] of DSEAR. DSEAR being the 'Dangerous Substances and Explosive Atmospheres Regulations 2002', these regulations are enforced by the HSE (Health \& Safety Executive) or the local authority.

\section{Risk assessment}

The purpose of the risk assessment is to provide an employer with the information required to eradicate or reduce hazards that could potentially harm workers. By carefully examining and identifying the dangerous substances present in the workplace; the work activities that involve the use of these substances; and their particular characteristics, an employer is able to protect both workers and the public as much as possible from potential explosions, fires or other incidents leading to damage to their facility or worse, injury to employees and members of the public.

The four key points to consider when carrying out a risk assessment are:

1. The specific hazardous properties of the substances.

2. How the substances are used and stored.

3. The likelihood of a potentially explosive atmospheres occurring.

4. What potential ignition sources are/would be present.

Risk assessments should be carried out irrespective of the amount of potentially explosive material present, this is good practice as it allows employers to evaluate the effectiveness of existing safety measures and whether additional precautions should be implemented. Specific attention should be given to any work activities which are not always routine, for example maintenance work. There can be a greater chance of incidents happening during maintenance related activities due to their sometimes unscheduled nature. 
Risk assessments should be reviewed regularly and additional assessments should be carried out before the introduction of new hazardous substances or any alterations or extensions to existing facilities

\section{Training requirements}

Employers are required to issue suitable training and relevant information to workers and any other personnel with access to potentially hazardous areas. This will mainly highlight how to conduct themselves along with other necessary actions required to safeguard themselves and others, including:

- $\quad$ The name of substances in use and risks they may present.

- $\quad$ Provide access to any relevant material safety data sheets.

- Specific details of legislation that applies to the hazardous properties of those substances.

- $\quad$ Details of the risk assessment.

Training need only be provided to non-workers where it is required to ensure their safety. This would normally included visitors to a facility. When provided to non-workers it should be at a level proportional to the potential risks.

\section{Equipment}

The use of standard off-the-shelf electric powered tools in hazardous areas is strictly controlled. Usually a permit to work system will exist for the use of non-certified equipment in a potentially explosive area; these are commonly referred to as 'hot permits'. These permits are issued by personnel responsible for the safety of a particular area and can take a couple of days to obtain in some cases. Alternatively, equipment specifically designed and certified for use in these areas may be available. Ultimately it is the workers responsibility to select equipment suitable for their particular workplace. Likewise manufacturers and suppliers of certified equipment destined for use in potentially explosive workplaces in Europe also have a duty to ensure the equipment is manufactured accordingly.

There are different types of certified equipment that can be used within potentially explosive workplaces, this equipment is designed to ensure that the potential to cause an explosion is removed or greatly reduced. This equipment must be designed and manufactured in accordance with particular design methods known as protection concepts. Basically these protection concepts either contain an explosion within the equipment, or the equipment is designed not to produce sufficient energy to create a spark and generate an explosion. Table 3 highlights some of the types of protection concepts manufacturers use when developing equipment.

Table 3. Types of Protection

\begin{tabular}{|c|c|c|c|}
\hline $\begin{array}{l}\text { Protection } \\
\text { Concept }\end{array}$ & $\begin{array}{l}\text { Protection } \\
\text { Name }\end{array}$ & $\begin{array}{l}\text { International } \\
\text { Standard }\end{array}$ & $\begin{array}{l}\text { Suitable } \\
\text { For Zone }\end{array}$ \\
\hline Exd & Flameproof & IEC/EN 60079-1 & 1 \\
\hline Exe & Increased Safety & IEC/EN 60079-7 & 2 or 1 \\
\hline Exo & Oil Immersion & IEC/EN 60079-6 & 2 or 1 \\
\hline Exq & Powder Filled & IEC/EN 60079-5 & 2 or 1 \\
\hline Exm & Encapsulation & IEC/EN 60079-18 & $\begin{array}{l}0 \text { (Ex ma) } \\
1 \text { (Ex mb) }\end{array}$ \\
\hline Exp & Pressurised & IEC/EN 60079-2 & $\begin{array}{c}1 \text { (Ex px/py) } \\
2(\text { (Ex pz) }\end{array}$ \\
\hline Exi & Intrinsically Safe & $\begin{array}{l}\text { IEC/EN 60079-25 } \\
\text { IEC/EN 60079-11 } \\
\text { IEC/EN 60079-27 }\end{array}$ & $\begin{array}{l}0 \text { (Ex ia) } \\
1 \text { (Ex ib) } \\
2 \text { (Ex ic) }\end{array}$ \\
\hline Exn & Non-Sparking & $\begin{array}{l}\text { IEC/EN 60079-15 } \\
\text { IEC/EN 60079-27 }\end{array}$ & 2 \\
\hline
\end{tabular}




\subsection{Commonly used protection concepts}

Intrinsically Safe (Ex i)

This type of protection is based on the restriction of electrical energy within the equipment and of interconnecting wiring exposed to the potentially explosive atmosphere to a level below that which can cause ignition by either sparking or heating effects.

\section{Flameproof (Ex d)}

This type of protection places the parts which could potentially ignite an explosive atmosphere into an enclosure. The enclosure can withstand the pressure developed during an internal explosion or arc producing components, and prevents the transmission of the explosion to the external explosive gas atmosphere surrounding the enclosure.

\subsection{Equipment markings}

Any equipment destined for use within a potentially hazardous area must carry specific markings in line with Directive 94/9/EC [13] (ATEX 95) and IEC/EN 60079-0 [14]. These markings are in addition to the required CE mark and further explained in Figure 3.

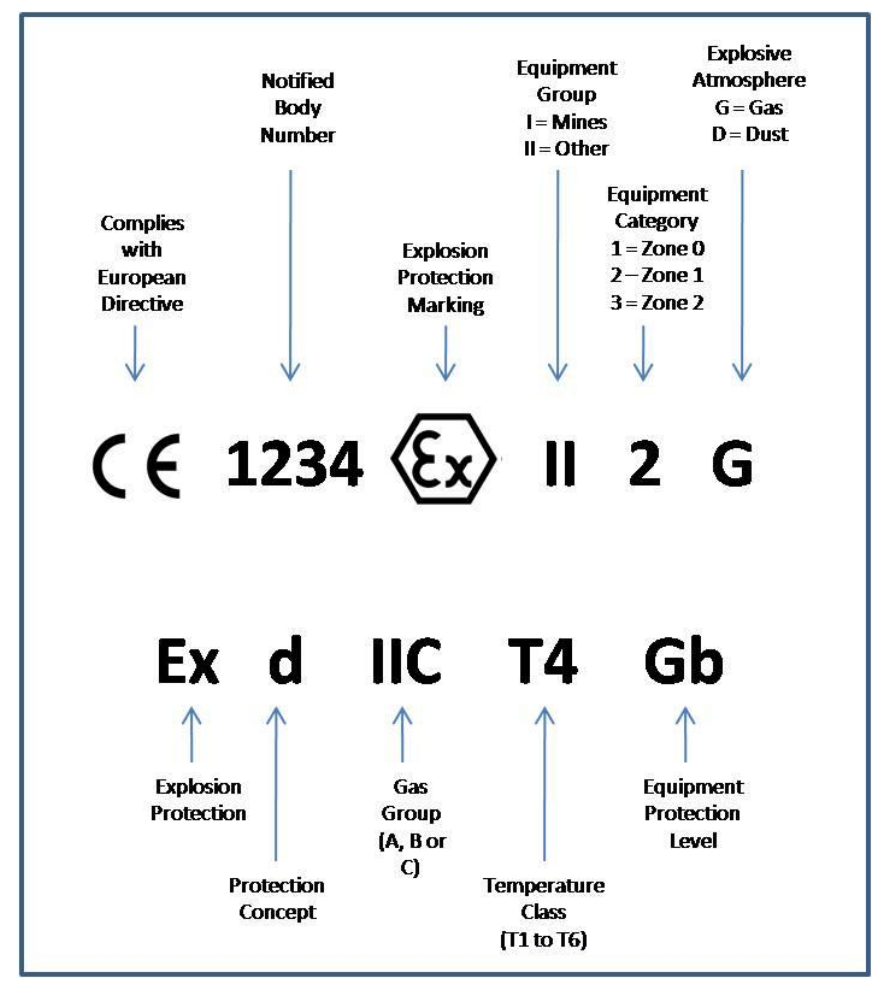

Fig. 3. Breakdown of Ex Markings

Where appropriate the equipment marking will include the following information:

- Manufacturers company name and address

- Certificate number \& name of issuing body

- Serial number and year of manufacture

- $\quad$ Specific Ex marking - see Fig. 3 
- Ambient temperature ranges other than the standard $-20^{\circ} \mathrm{C} \leq \mathrm{Ta} \leq+40^{\circ} \mathrm{C}$ must be marked

- $\quad$ The CE mark

\subsection{Temperature in relation to equipment}

\section{Auto-ignition temperature}

This is the temperature at which the substance will ignite without a specific heat source being present. Each flammable substance is categorized using six different temperature classes, commonly known as the "T" rating, where the higher the T-rating the lower the gases auto-ignition temperature. See Table 2.

\begin{tabular}{|c|c|c|}
\hline T-Rating & $\begin{array}{c}\text { Auto Ignition } \\
\text { Temperature }\end{array}$ & Volatility \\
\hline T1 & $>450^{\circ} \mathrm{C}$ & $\begin{array}{c}\text { Least } \\
\text { Hazardous }\end{array}$ \\
\hline T2 & $>300^{\circ} \mathrm{C}$ \\
\hline T3 & $>200^{\circ} \mathrm{C}$ \\
\hline T4 & $>135^{\circ} \mathrm{C}$ \\
\hline T5 & $>100^{\circ} \mathrm{C}$ \\
\hline T6 & $>85^{\circ} \mathrm{C}$ & Most \\
\hline
\end{tabular}

For example, if a substance has an auto ignition temperature of $180^{\circ} \mathrm{C}$, then it would be safe to use equipment which is marked T6, T5 or T4. It would not be safe to use equipment marked T3, T2 or T1 as this equipment could exhibit surface temperatures which are hot enough to ignite the hazardous atmosphere.

\section{Operational temperature}

The environmental temperature is also very important when using electrical equipment in a hazardous area. Any equipment certified for use within a potentially hazardous area has an operational temperature. This is commonly referred to as the "Tamb". This ambient temperature highlights the maximum and minimum environmental temperatures at which the equipment is approved to be used in. Referring to the standard IEC/EN 60079-0 [15], the normal limits are $-20^{\circ} \mathrm{C}$ to $+40^{\circ} \mathrm{C}$. Where the operation temperatures of the equipment falls within this range no additional marking is required on the equipment. However, if they are outside this range the specific temperature range must be clearly marked.

\section{Conclusion}

Information and education on safety related topics are significantly helpful tools when working in potentially hazardous areas. An understanding of the minimum requirements outlined in this paper can potentially improving the reliability and productivity of a facility, whilst more importantly improving the safety of workers by increasing their awareness of these guidelines.

\section{References}

[1] IEC 60079-10-1 - Explosive atmospheres - Part 10-1: Classification of areas - Explosive gas atmospheres ed.1.0, 2008.

[2] DIRECTIVE 1999/92/EC of the European Parliament and of the Council of $16^{\text {th }}$ December 1999.

[3] Annex I, DIRECTIVE 1999/92/EC of the European Parliament and of the Council of $16^{\text {th }}$ December 1999.

[4] Annex II, DIRECTIVE 1999/92/EC of the European Parliament and of the Council of $16^{\text {th }}$ December 1999.

[5] Annex I, DIRECTIVE 1999/92/EC of the European Parliament and of the Council of $16^{\text {th }}$ December 1999.

[6] Annex II, DIRECTIVE 1999/92/EC of the European Parliament and of the Council of $16^{\text {th }}$ December 1999.

[7] Council Directive 89/655/EEC of 30 November 1989 concerning the minimum safety and health requirements for the use of work equipment by workers at work (second individual Directive within the meaning of Article 16 (1) of Directive 89/391/EEC)

[8] DIRECTIVE 1999/92/EC OF THE EUROPEAN PARLIAMENT AND OF THE COUNCIL of 16 December 1999 
on minimum requirements for improving the safety and health protection of workers potentially at risk from explosive atmospheres (15th individual Directive within the meaning of Article 16(1) of Directive 89/391/EEC).

[9] DIRECTIVE 1999/92/EC OF THE EUROPEAN PARLIAMENT AND OF THE COUNCIL of 16 December 1999 on minimum requirements for improving the safety and health protection of workers potentially at risk from explosive atmospheres (15th individual Directive within the meaning of Article 16(1) of Directive 89/391/EEC).

[10] DIRECTIVE 1999/92/EC OF THE EUROPEAN PARLIAMENT AND OF THE COUNCIL of 16 December 1999 on minimum requirements for improving the safety and health protection of workers potentially at risk from explosive atmospheres (15th individual Directive within the meaning of Article 16(1) of Directive 89/391/EEC).

[11] Regulation 7- Places where explosive atmospheres may occur, The Dangerous Substances and Explosive Atmospheres Regulations 2002 (DSEAR).

[12] Regulation 11- Duty of co-ordination, The Dangerous Substances and Explosive Atmospheres Regulations 2002 (DSEAR).

[13] Directive 94/9/EC of the European Parliament and the Council of 23 March 1994 on the approximation of the laws of the Member States concerning equipment and protective systems intended for use in potentially explosive atmospheres.

[14] IEC/EN 60079-0 - Explosive atmospheres - Part 0: Equipment - General requirements - ed.6.0, 2011.

[15] IEC/EN 60079-0 - Explosive atmospheres - Part 0: Equipment - General requirements - ed.6.0, 2011. 